\title{
ROLE OF MONTELUKAST IN PREVENTING RELAPSE IN CHILDHOOD IDIOPATHIC NEPHROTIC SYNDROME: A QUASI-EXPERIMENTAL STUDY
}

\author{
Hashim Raza ${ }^{\square}$, Muhammad Imran', Khuram Rashid', Shahid Ishaq', Waqas Shakir ${ }^{2}$, Mudasser Adnan ${ }^{3}$
}

\section{ABSTRACT}

OBJECTIVE: To study the role of montelukast in preventing relapses in childhood idiopathic steroid sensitive nephrotic syndrome (SSNS).

METHODS: This quasi-experimental, open label study was conducted at Department of Paediatric Nephrology, The Children's Hospital and The Institute of Child Health, Multan, Pakistan. Total of 106 patients with firstepisode of nephrotic syndrome aged I- 10 years were enrolled from FebruaryMay 2019 and non-randomly assigned to Group-A \& Group-B (53 patients in each group). All patients in both groups were started on prednisolone $2 \mathrm{mg} / \mathrm{kg}$ single morning dose for 4-weeks as per institutional protocol. Group-A (Cases) also received montelukast $5 \mathrm{mg}$ daily at bedtime for at least 12 months while Group-B (control) was not given montelukast. All patients were followed up for one year till May 2020 to monitor the response to treatment and evidence of relapse. Ten patients were excluded from final analysis due to loss to follow-up ( $n=3 ; 2$ in Group-A and I in Group-B) or showing steroid resistance $(n=7 ; 3$ in Group-A and 4 in Group-B).

RESULTS: Out of 96 children (48 each in Group-A \& B), 58 (60.4\%) were males. Mean age was $4.7 \pm 1.9$ years and most of children $(n=64 ; 66.7 \%)$, were aged between 2-6 years. Overall relapse rate of $35.4 \%(n=34 / 98)$ was observed, with 9/48 (I8.8\%) patients in Group-A compared to 25/48 (52.1\%) patients in Group-B $(\mathrm{p}<0.00 \mathrm{I})$. Out of 34 patients with relapse, $20(58.8 \%)$ were males and $14(41.2 \%)$ were females.

CONCLUSION: Montelukast showed significant efficacy in preventing relapse rate in children with SSNS during one year of follow-up.

\section{Clinical Trial Registry Number: NCT048I 8723}

KEY WORDS: Leukotriene Antagonists (MeSH); Montelukast (MeSH); Nephrotic Syndrome (MeSH); Steroids (MeSH); Relapse (MeSH); Recurrence (MeSH); Child (MeSH); Child, Preschool (MeSH).

THIS ARTICLE MAY BE CITED AS: Raza H, Imran M, Rashid K, Ishaq S, Shakir W, Adnan M. Role of montelukast in preventing relapse in childhood idiopathic nephrotic syndrome: a quasi-experimental study. Khyber Med Univ J 202I; I3(2):66-70. https://doi.org//0.35845/kmuj.202I.20903.

\section{INTRODUCTION}

diopathic nephrotic syndrome (NS) is the commonest glomerular disease in children described as heavy proteinuria $\left(>\mathrm{Ig} / \mathrm{m}^{2} /\right.$ day) leading to hypoalbuminemia $(<2.5 \mathrm{~g} / \mathrm{dl})$, progressive generalized edema, and hyperlipidemia.' Majority of these children have steroid sensitive NS (SSNS) with minimal change disease (MCD) being the most frequent histopathology. ${ }^{2}$ However, a vast majority (about $60-80 \%$ ) of these children relapse while still on a dose of steroids or after discontinuation of steroid therapy.' Relapses are treated with similar steroid courses putting the patients at increased risk of steroid toxicity. Therefore, every attempt should be made to prevent relapse in these patients. Various measures have been adopted in this regard like adding other immunosuppressive drugs to the treatment regimen, extending the course of steroid treatment with slow
I: Department of Pediatric Nephrology, The Children's Hospital and The Institute of Child Health, Multan, Pakistan

2: Department of Pediatric Medicine, The Children's Hospital and The Institute of Child Health, Multan, Pakistan

3: Department of Pediatric Cardiology, The Children's Hospital and The Institute of Child Health, Multan, Pakistan

Email网: drhashim143@gmail.com

Contact \# : +92-321-4343304

Date Submitted: October 07, 2020

Date Revised: April 02, 2021

Date Accepted: April 12,2021

prolonged tapering etc. But all these regimens are associated with significant side effects of drugs and also may not be cost effective in our circumstances.

The histopathological hallmark of minimal-change nephrotic syndrome (MCNS) is the foot-process (FP) effacement of podocytes in the epithelium of glomerular capillaries as seen on electron microscopy. ${ }^{3}$ Physiologically, the FPs remain wide open to serve as a passage for glomerular filtrate and are held together by tenuous slit diaphragms (SD) that connect the filtration slits. Glomerular SDs are a major selective barrier for proteins and are thought to be modified junctions adherens comprised of various proteins like nephrin, CD-2 associated protein (CD2AP), Neph- I , -2, -3, podocin, zona occludens-I (ZO-I). ${ }^{4}$ In MCNS the ultrastructural changes in podocytes lead to altered permselectivity of the SD glomerular filtration barrier.

Recently, some researchers have pointed out raised interleukin- I3 (ILI3), a leukotriene, leading to podocytes injury which in turn resulting into inducing minimal change like nephropathy. ${ }^{5,6}$ Overexpression of IL- I 3 cause down-regulation of nephrin, podocin, and dystroglycan, which are essential for ensuring the integrity of SDs. IL- I 3 was also shown to affect ZO-I leading to development of proteinuria in MCNS. ${ }^{7}$ 
TABLE I: COMPARISON OF BASELINE CHARACTERISTICS OF STUDY PARTICIPANTS

\begin{tabular}{|c|c|c|c|c|c|}
\hline \multicolumn{2}{|c|}{ Characteristics } & $\begin{array}{l}\text { Group-A } \\
\text { (received }\end{array}$ & $\begin{array}{l}\text { Group-B } \\
\text { (Did not receive }\end{array}$ & $\begin{array}{c}\text { Total } \\
(n=96)\end{array}$ & P-Value \\
\hline \multirow{2}{*}{ Gender } & Male & $32(66.7 \%)$ & $26(54.2 \%)$ & $58(60.4 \%)$ & \multirow{2}{*}{0.2105} \\
\hline & Female & $16(33.3 \%)$ & $22(45.8 \%)$ & $38(39.6 \%)$ & \\
\hline \multirow{3}{*}{$\begin{array}{l}\text { Age } \\
\text { Groups } \\
\text { (year) }\end{array}$} & $\mathrm{I}-2$ & $5(10.4 \%)$ & $8(16.7 \%)$ & $13(13.5 \%)$ & \multirow{3}{*}{0.6179} \\
\hline & $>2-6$ & 30 (62.5\%) & 27 (56.3\%) & $57(59.4 \%)$ & \\
\hline & $>6-10$ & $12(25.0 \%)$ & 14 (29.2\%) & $26(27.1 \%)$ & \\
\hline
\end{tabular}

Leukotrienes are involved in inflammatory cells recruitment, bronchoconstriction, vasodilatation, enhanced microvascular permeability, exudation of macromolecules, and edema; these interactions are well described in the pathogenesis of asthma. ${ }^{8}$ Similarly, in the kidney, leukotrienes induce an immune mediated injury. IL-I 3 was shown to redistribute and reduce the $\mathrm{ZO}-\mathrm{I}$ proteins leading to disruption of glomerular filtration barrier in SD and effacement of FPs resulting in minimal change disease (MCD) like nephropathy and development of proteinuria.' As many children with nephrotic syndrome are atopic, similar inflammatory effects of leukotrienes are thought to play a major role in the pathogenesis of nephrotic state. Montelukast has been shown in experimental models to restore the IL-I3 induced human podocytes dysfunction. ${ }^{7}$ Therefore, we hypothesized that montelukast may have a role in preventing relapse in SSNS by inhibiting increased production of IL- 13 by CD3+, CD4+, and CD8+ T cells. So, this study was conducted to know the role of leukotriene receptor antagonist (LTRA) montelukast in preventing relapses in idiopathic childhood nephrotic syndrome (NS).

\section{METHODS}

This open label, quasi-experimental study was conducted at the Department of Paediatric Nephrology, The Children's Hospital \& The Institute of Child Health, Multan, Pakistan. A total of 106 children, aged 1-10 years with idiopathic NS, selected through non-probability consecutive sampling method were enrolled from February to May 2019. Study was approved from the Institutional Ethical Committee (Ref No.33, Dated 15-0I-2019). This trial was registered as Clinical Trial Registry Number NCT048I8723 at https:// clinicaltrials.gov/. Patients having previously documented steroid resistant nephrotic syndrome (SRNS) or those having nephrotic syndrome with atypical features or secondary cause were excluded from the study.

Selected patients were nonrandomly assigned into two groups: 53 in GroupA (Case group who were given prednisolone along with montelukast $5 \mathrm{mg}$ at bedtime) and 53 in Group-B (Control-group who were given prednisolone alone without montelukast). All patients in both the groups were induced with prednisolone $2 \mathrm{mg} / \mathrm{kg}$ single morning dose with breakfast for a total 4 weeks. Patients who did not achieve remission after 4 weeks' full dose were labelled as SRNS and were excluded from the study. Children with SSNS were further treated by prednisolone $1.5 \mathrm{mg} / \mathrm{kg}$ single morning dose with breakfast every other day for the next 4 weeks. Prednisolone was then tapered by reducing $25 \%$ dose weeks. Patients in the Group-A continued taking montelukast after stopping steroids. All patients were followed up every 4-8 weeks for a minimum of 12 months till May 2020, to look for the response to treatment, side effects of medications, other co-morbidities, and the number of relapses. Relapses were treated with repeat prednisolone doses according to the protocol of treatment for relapse.

There were 3 patients who were lost to follow-up ( 2 in Group-A and $I$ in Group-B) while 7 patients did not achieve remission after 4 weeks' and labelled as SRNS (3 in Group-A and 4 in Group-B). All these 10 patients were fortnightly and completely stopped in 8 excluded from final analysis (figure I).

NS was defined as heavy proteinuria (> IG/ $\mathrm{m}^{2} /$ day or a spot urinary protein creatinine ratio $>2 \mathrm{mg} / \mathrm{mg}$ ), hypoalbuminemia $(<2.5 \mathrm{G} / \mathrm{dl})$, progressive generalized edema, and hypercholesterolemia $(>220 \mathrm{mg} / \mathrm{dl}) .^{10}$ Remission was defined as nil or trace proteinuria for 3 consecutive days." Relapse was labelled as recurrence of proteinuria $3+$ or more for 3 consecutive days with or without edema. SSNS was labelled as a child who achieved remission within 4 weeks of steroid therapy (Prednisolone $2 \mathrm{mg} / \mathrm{kg} /$ day). SRNS was labelled as a child who did not go into remission despite 4 weeks of daily prednisolone $2 \mathrm{mg} / \mathrm{kg} /$ day. ${ }^{.}$

Data was analysed using SPSS version 26.0. Frequencies and percentages were represented for study variables like gender, age, and relapse. Chi square test was applied to compare study variables between both study groups considering $p$ value $<0.05$ as significant.

\section{RESULTS}

After excluding 10 patients ( 5 from each Group-A \& Group-B) who were lost to follow-up $(n=3)$ or showed no response to steroids in 4 weeks $(n=7)$, 96 patients (48 in each group) were included in the final analysis as shown in Figure I. Overall, mean age was noted to be $4.7 \pm 1.9$ years while most of the children $(n=57 / 96 ; 59.4 \%)$ were between age 2-6 years (Table I). Gender wise, $58(60.4 \%)$ were males with male to female ratio of $1.5: \mathrm{I}$.

Thirty-four (35.4\%) patients developed relapse. Out of these 34 relapsing patients, $25(73.5 \%)$ patients were in group-B who were not given montelukast whilst only 9 (26.5\%) patients were in the Group-A given montelukast. In Group-A (received montelukast) the relapse rate was $18.8 \%(n=9 / 48)$ as compared to $52.1 \%$ $(n=25 / 48)$ in Group-B who did not receive montelukast $(<0.00 \mathrm{I})$.

No significant relation of gender with children having relapse was observed $(p=0.8|3|)$. However, relapse rate turned out to be significantly linked with age as more children in the age range $1-2$ years $(29.4 \%$ vs $4.8 \%)$ relapsed compared with older children $(p=0.0027)$. 
TABLE II: RELAPSE IN PATIENTS OF CHILDHOOD IDIOPATHIC NEPHROTIC SYNDROME

\begin{tabular}{|c|c|c|c|c|}
\hline \multirow{2}{*}{\multicolumn{2}{|c|}{ Characteristics }} & \multicolumn{2}{|c|}{ Relapse } & \multirow{2}{*}{ P-Value } \\
\hline & & \multirow{2}{*}{$\begin{array}{c}\text { Yes }(n=34) \\
9(26.5 \%)\end{array}$} & \multirow{2}{*}{$\begin{array}{l}\text { No }(n=62) \\
39(62.9 \%)\end{array}$} & \\
\hline \multirow{2}{*}{ Study Groups } & $\begin{array}{l}\text { Group-A } \\
\text { (Received Montelukast) }(n=48)\end{array}$ & & & \multirow{2}{*}{$<0.001$} \\
\hline & $\begin{array}{l}\text { Group-B } \\
\text { (No Montelukast) }(n=48)\end{array}$ & $25(73.5 \%)$ & $23(37.1 \%)$ & \\
\hline \multirow{2}{*}{ Gender } & Male $(n=58)$ & $20(58.8 \%)$ & 38 (61.3\%) & \multirow{2}{*}{0.8131} \\
\hline & Female $(n=38)$ & $14(41.2 \%)$ & 24 (38.7\%) & \\
\hline \multirow{3}{*}{ Age Groups (years) } & $1-2(n=13)$ & $10(29.4 \%)$ & $3(4.8 \%)$ & \multirow{3}{*}{0.002} \\
\hline & $>2-6(n=57)$ & $15(44.1 \%)$ & $42(67.7 \%)$ & \\
\hline & $>6-10(n=26)$ & $9(26.5 \%)$ & $17(27.4 \%)$ & \\
\hline
\end{tabular}

Tables II show the comparison of relapse rate between the two study groups as well as its relationship with gender and age.

\section{DISCUSSION}

In our study, the relapse rate in childhood idiopathic steroid sensitive nephrotic syndrome cases was $35.4 \%$. Relapse rate was significantly lower (18.8\%) in patients who received montelukast along with steroids as compared to patients who received steroid alone (52.1\%).

Nephrotic syndrome in children mostly responds to treatment with oral prednisolone. However, a vast majority of patients do relapse on either stopping steroids or during tapering of steroid therapy. ${ }^{12}$ These relapsing children are again treated with steroids and sometimes with additional immunosuppressive medications if they relapse frequently or become steroid dependent. So, these children suffer serious medication related complications. Paediatric nephrologists are always anxious to take such measures as to decrease the number of relapses in such cases; thus, ultimately, aiming at decreasing morbidity.

Montelukast (LTRA) inhibits the proinflammatory effects of leukotrienes and is widely being recommended as a prophylactic drug to decrease the number of exacerbations in asthma in both children and adults. Many children with nephrotic syndrome also show atopy and have concomitant bronchial asthma. ${ }^{13-16}$ Leukotrienes induce similar immune mediated injury in kidneys. ILI 3 was shown, in experimental models on human podocytes by Park SJ et al, to redistribute and reduce the $\mathrm{ZO}-\mathrm{I}$ proteins leading to disruption of from Singapore Chinese children with MCNS showed IL- I 3 genetic polymorphisms. ${ }^{18}$ Overexpression of IL- 13 has been shown to induce minimal change like nephropathy in rats. ${ }^{16}$

Zedan $M M$ et al determining if montelukast had any beneficial effects in steroid dependent NS, ${ }^{19}$ revealed that plasma leukotriene B4 and LTC4/D4/E4 were significantly reduced among children treated with montelukast. Clinically, they concluded that percentage of SDNS children who were given montelukast was higher in terms of being off prednisolone for longer time, dose of prednisolone lower on relapse, and rapid prednisolone tapering as compared to the children who were not given montelukast. So, they suggested that montelukast be used as an add-on therapy in children with SDNS.

Keeping in mind the above mentioned studies, we hypothesized that montelukast may have a role in preventing relapse in SSNS by inhibiting production of IL- 13 by CD3+, CD4+, and CD8+ $T$ cells. The main initiative for this study

came from the study by Park SJ et al who increased IL-13 mRNA expression relapse in childhood NS. Wei CL et al

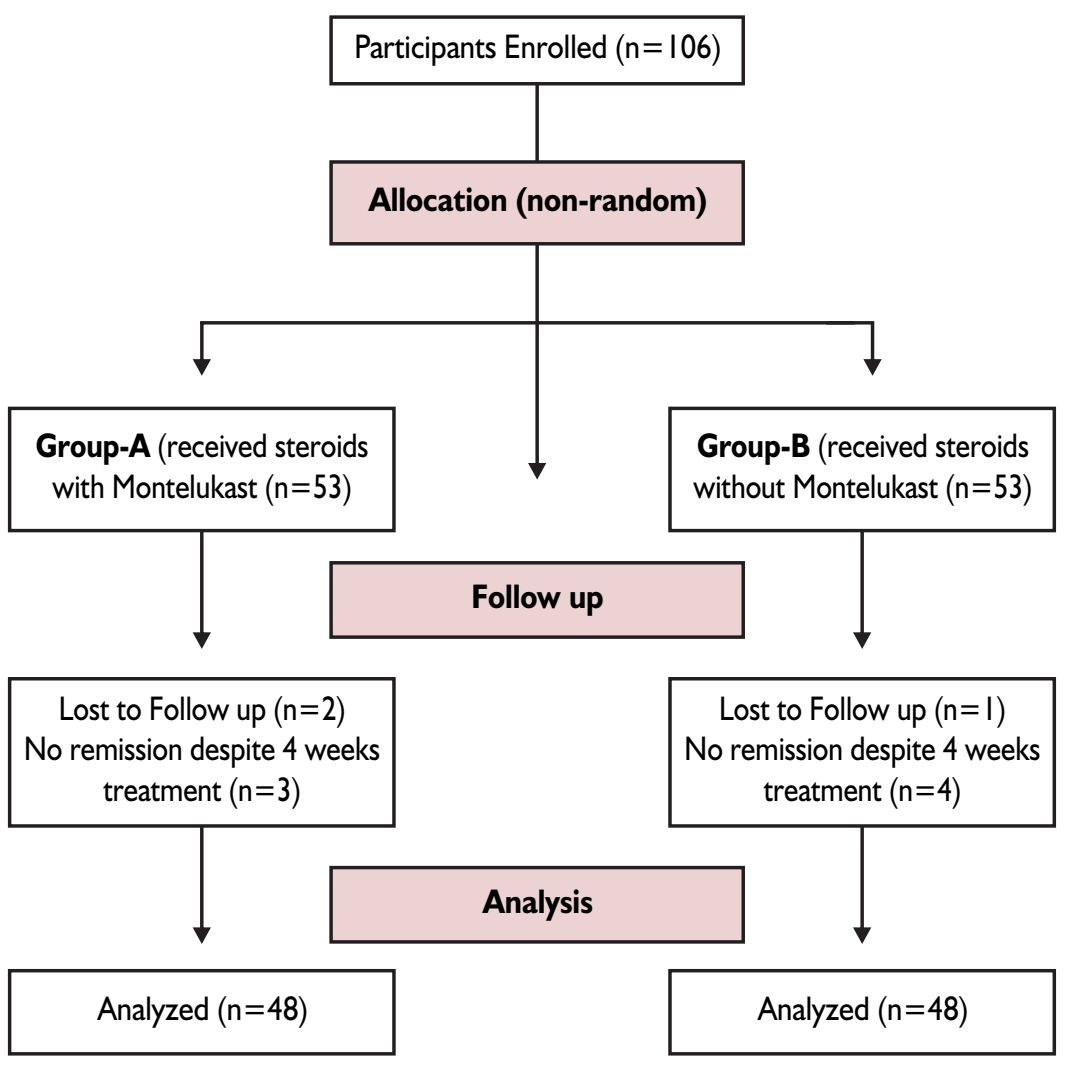

Figure I: Methodology flow chart 
showed that higher concentrations of interlukin-I3 (IL-I3) increased the disruption of glomerular filtration barrier in SD and FP effacement. ${ }^{17}$ They also showed that ZO-I proteins were redistributed and reduced in IL- 13 treated human podocytes, which was significantly restored after treatment with an LTRA montelukast.

The present study is first of its kind in childhood nephrotic syndrome in our country where we investigated if there is any role of montelukast in preventing relapse in SSNS. It was observed that the first relapse of NS did occur in only $18.8 \%$ SSNS children who were given montelukast $5 \mathrm{mg}$ at bedtime along with steroid therapy. Steroids were stopped after 4 months of treatment as per our institutional protocol. However, montelukast was continued for further 8 months (total 12 months). On the comparison, the rate of relapse in SSNS children who were not given montelukast (Group-B) was $52.1 \%$ which is significantly higher $(p=0.0006)$ than Group-A given montelukast.

\section{LIMITATIONS}

This was an open-label, non-blinded, quasi-experimental, single centre study in which we non-randomly assigned patients into 2 groups (every alternate patient given montelukast). We also did not take into consideration confounding variables like presence of asthma or atopy, and any associated side effects of montelukast. We recommend further large, multicentred randomized controlled trials to evaluate Montelukast's role in childhood nephrotic syndrome.

\section{CONCLUSION}

Our study shows that montelukast may have a significant role in preventing or decreasing relapse rate in idiopathic SSNS among children. More studies involving multiple centers, larger sample sizes and longer follow ups may further elucidate the efficacy of montelukast in childhood NS.

\section{ACKNOWLEDGMENT}

The authors would like to thank Muhammad Aamir (Research Consultant, Bahawalpur) for his volunteer assistance in statistical analysis of this research.

\section{REFERENCES}

I. Eltigani A, Nahla E, Mohamed A, Rashid E, Gada O. Childhood steroid sensitive nephrotic syndrome: Characteristics and predictors of relapses; a study at a single center in Khartoum. Sudan J Med Sci 2018;13(3):133-43. https://doi.org/ 10.18502/sjms.v|3i3.2952

2. Lane BM, Cason $\mathrm{R}$, Esezobor $\mathrm{Cl}$, Gbadegesin RA. Genetics of childhood steroid sensitive nephrotic syndrome: An update. Front Pediatr 2019;7:8. https://doi.org/l0.3389/fped.2019. 00008

3. Ranganathan S. Pathology of podocytopathies causing nephrotic syndrome in children. Front Pediatr 2016;4:32. https://doi.org/ 10.3389/fped.2016.00032

4. Leung $A K$, Wong $A H$. Proteinuria in children. Am Family Physician 20I0;82(6):645-5।.

5. Eddy AA, Symons JM. Nephrotic syndrome in childhood. Lancet 2003;362:629-39. https://doi.org/ |0.10|6/S0|40-6736(03) |4|84-0

6. Alberto Z, de Oliveira AL, Araujo MJ, Leite NR, de Martins S, de Pinheiro MC, et al. Steroid-resistant idiopathic nephrotic syndrome in children: long-term follow-up and risk factors for end-stage renal disease. J Bras Nefrol 2013;35(3): 191-9. https://doi.org//0.5935/ 0I0I-2800.20I3003 I

7. Kurihara $\mathrm{H}$, Anderson JM, Farquhar MG. Increased Tyr phosphorylation of ZO-I during modification of tight junctions between glomerular foot processes. Am J Physiol 1995;268: F5I4-24. https://doi.org/10.1152/ ajprenal. I995.268.3.F5। 4

8. Yap HK, Cheung W, Murugasu B, Sim SK, Seah CC, Jordan SC. Th I and Th2 cytokine mRNA profiles in childhood nephrotic syndrome: evidence for increased IL- I 3 mRNA expression in relapse. J Am Soc Nephrol 1999; 10:529-37.

9. Cheung W, Wei CL, Seah CC, Jordan SC, Yap HK. Atopy, serum $\operatorname{lgE}$, and interleukin-I3 in steroidresponsive nephrotic syndrome.
Pediatr Nephrol 2004;19:627-32. https://doi.org/ I0.1007/s00467004-1438-8

10. Abitbol C, Zilleruelo G, Freundlich $M$, Strauss J. Quantitation of proteinuria with urinary protein/ creatinine ratios and random testing with dipsticks in nephrotic children. J Pediatr 1990; I I 6(2):243-7.

II. Bagga A. Revised guidelines for management of steroid-sensitive nephrotic syndrome. Indian J Nephrol 2008; I8(I):3 I-9. https://doi.org/10.4103/097I 4065.4I 289

12. Webb NJA, Woolley RL, Lambe T, Frew E, Brettell EA, Barsoum EN, et al. Long term tapering versus standard prednisolone treatment for first episode of childhood nephrotic syndrome: phase III randomised controlled trial and economic evaluation. BMJ 2019; 365:II800. https://doi.org/10.1136/ bmj.II 800

13. Niimi A. Cough, asthma, and cysteinyl-leukotrienes. Pulm Pharmacol Ther 2013;26:5।4-9. https://doi.org/10.1016/j.pupt.2013 .06 .003

14. Forbes TA, Lunn AJ. Montelukast: a novel therapeutic option in eosinophilic peritonitis. Pediatr Nephrol 20|4;29:|279-82. https://doi.org/ 10.1007/s00467-013-27/8-y

15. Bisgaard H. Pathophysiology of the cysteinyl leukotrienes and effects of leukotriene receptor antagonists in asthma. Allergy 200I;56 (Suppl 66):7-II. https://doi.org/10.1034/ j.1398-9995.56.s66.2.x

16. Lai KW, Wei CL, Tan LK, Tan PH, Chiang GS, Lee CG, et al. Overexpression of interleukin-I 3 induces minimal-change-like nephropathy in rats. J Am Soc Nephrol 2007; I 8:|476-85. https://doi.org/ 10.168I/ASN.20060707I0

17. Park SJ, Saleem MA, Nam JA, Ha TS, Shin JI. Effects of interleukin- 13 and montelukast on the expression of zonula occludens-I in human podocytes. Yonsei Med J 2015;56 (2):426-32. https://doi.org/ I0.3349/ymj.20I5.56.2.426 
18. Wei CL, Cheung W, Heng CK, Arty $\mathrm{N}$, Chong SS, Lee BW, et al. Interleukin-I 3 genetic polymorphisms in Singapore Chinese children correlate with long-term outcome of minimal-change disease. Nephrol
Dial Transplant 2005;20:728-34. https://doi.org/ 10.1093/ndt/gfh648

19. Zedan MM, El-Refaey A, Zaghloul $H$, Abdelrahim ME, Osman A, Zedan MM, et al. Montelukast as an add-on treatment in steroid dependant nephrotic syndrome, randomised-controlled trial. J Nephrol 2016;29(4):585-92. https://doi.org/10.1007/s40620016-0297-2

\section{AUTHOR'S CONTRIBUTION}

Following authors have made substantial contributions to the manuscript as under:

HR: Conception and study design, acquisition of data, drafting the manuscript, approval of final version to be published

MI: Conception and study design, drafting the manuscript, critical review, approval of final version to be published

KR \& MA: Acquisition of data, drafting the manuscript, approval of final version to be published

SI \& WS: Analysis and interpretation of data, drafting the manuscript, approval of final version to be published

Authors agree to be accountable for all aspects of the work in ensuring that questions related to the accuracy or integrity of any part of the work are appropriately investigated and resolved.

\begin{tabular}{|c|}
\hline CONFLICT OF INTEREST \\
Authors declared no conflict of interest \\
GRANT SUPPORT AND FINANCIAL DISCLOSURE \\
Authors have declared no specific grant for this research from any \\
funding agency in the public, commercial or not-for-profit sectors
\end{tabular}

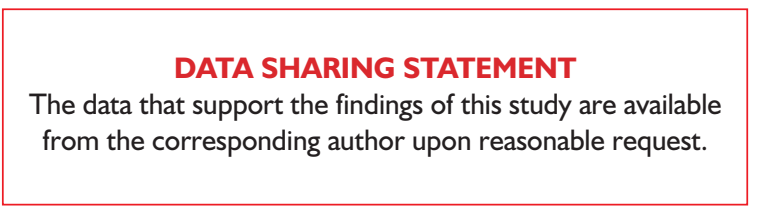

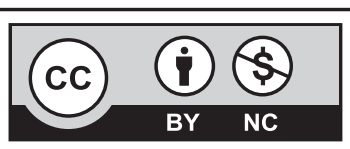

This is an Open Access article distributed under the terms of the Creative Commons Attribution-Non Commercial 2.0 Generic License.
KMUJ web address: www.kmuj.kmu.edu.pk

Email address: kmuj@kmu.edu.pk 